\title{
Ranking Canadian oil and gas projects using TOPSIS
}

\author{
Seyed Jafar Sadjadi and Soheil Sadi-Nezhad*
}

Department of Finance and Statistics, University of Waterloo, Waterloo, Canada

\begin{tabular}{|c|c|}
\hline CHRON I C LE & A B S T RACT \\
\hline $\begin{array}{l}\text { Article history: } \\
\text { Received: March 5, } 2017 \\
\text { Received in revised format: July } \\
16,2017 \\
\text { Accepted: August 2, } 2017 \\
\text { Available online: } \\
\text { August } 5,2017 \\
\text { Keywords: } \\
\text { Oil and gas industry } \\
\text { TOPSIS } \\
\text { Green gas effect }\end{array}$ & $\begin{array}{l}\text { One of the primary concerns for investment in oil and gas projects is to have a comprehensive } \\
\text { understanding on different issues associated with this industry. The industry is mainly influ- } \\
\text { enced by the price of oil and gas and in some events, many production units have been forced } \\
\text { to shut down solely because of low price of oil and gas. Environmental issues are other important } \\
\text { factors, which may put pressure on Canada's political affairs since the country has strong com- } \\
\text { mitment to reduce green gas effect. In this paper, we introduce a multi-criteria decision making } \\
\text { method, which helps us rank different projects in terms of investment. The proposed study con- } \\
\text { siders different investment factors including net present value, rate of return, benefit-cost anal- } \\
\text { ysis and payback period along with the intensity of green gas effects for ranking the present oil } \\
\text { and gas projects in Canada. }\end{array}$ \\
\hline
\end{tabular}

\section{Introduction}

During the past few years, various giant Canadian pipeline projects have been continuing to move through the approval process. There have been also an increase rate of pressures and industry lobbies have been pushing back against discussions that their projects would not compatible with actions on climate changes (Badiru \& Osisanya, 2016). There are presently various oil and gas projects underway in Canada including Northern Gateway, Energy East, Keystone XL, Trans Mountain, Pacific Northwest LNG, Eagle Mountain-Woodfibre gas pipeline and LNG facility and Line 9B. These projects need significant amount of investments and there are different risks involved for the accomplishment of any of these projects. The price and oil and gas is the main factor, which could justify investment in this industry. During the past two decades, oil price has gone up to near $150 \$$ which motivated many fund managers to pure money in this industry. However, there were events when the price of oil was as low as $45 \$$ and Canadian oil producers were forced to shut down their operations (Marcil et al., 2016).

Environment is another issue for the investment in this industry. This is a fact that oil industry has negative effects on environment. In fact, Canada's oil and gas industry is the biggest emitter of climate-

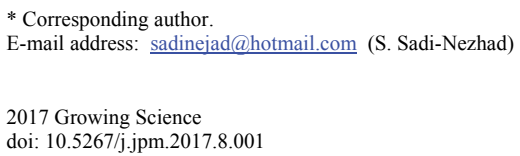


warming methane gas and a primary source of air pollutants recognized as volatile organic compounds, which are hazardous to human health. Methane is the primary source of natural gas which is used for heating homes and power factories. The new Canadian regulations will help oil and gas industry conserve natural gas which is presently wasted. This is one of the easiest actions Canada can take to reduce greenhouse gases in terms of investment, which could reduce green gas effect by 20 mega-tone a year, which is also equal to removing approximately five million passenger vehicles from the road each year. In addition, this will help Canada prevent the economic effects of global climate-change events such as drought and floods (Charpentier et al., 2009).

Fidler and Noble (2012) investigated strategic environmental assessment (SEA) practice and effect in three international offshore systems including Norway, Atlantic Canada and the United Kingdom to determine the challenges, lessons and opportunities for advancing SEA in offshore planning and evaluating the effects. They reported that SEA could help improve the efficiency of project-based assessment in the offshore sector.

Van Hinte et al. (2007) reviewed potential effects of the pipeline projects and developed a method to make an assessment on the current regime for evaluating project effects based on best practices criteria and reported that only three of 14 best practices criteria were met. The most substantial issues were to blame were absence of clear decision-making criteria; lack of decision-making processes that contain a legal obligation to include compensation to those negatively influenced by a project and ensure project advantages were equitably distributed; and no provision for relative evaluation of competing projects. Thomas et al. (2017) reviewed 58 articles published between 2009 and 2015 on public perceptions on oil and gas industry. They reported mixed levels of awareness of shale operations, tending toward higher awareness in areas with existing development.

Selection of an appropriate project in Canadian oil and gas industry plays essential role for investment purposes. Such decision is often involved different criteria, which are in conflict with each other such as risk and reward, green gas effect and profitability. There are many studies to find some efficient solutions, which could trade-off between such conflicting criteria such as Analytical hierarchy process (AHP) (Saaty, 1989), Technique for Order of Preference by Similarity to ideal Solution (TOPSIS) (Hwang \& Yoon, 1981), etc. Mahmoodzadeh et al. (2007), for instance, used both AHP and TOPSIS for ranking different projects based on four criteria; namely net present value, rate of return, benefitcost analysis and payback period. They also used fuzzy numbers to handle uncertainty associated with input data (Zadeh, 1997).

\section{The proposed study}

Selection of an oil and gas project is normally involved with various factors. Some of the factors are associated with financial data and profitability while others are involved with governmental regulations such as green gas effect.

\subsection{Factors influencing investment}

Fig. 1 demonstrates the factors considered in this study, which could influence an oil and gas project. As we can observe from Fig. 1, there are six factors associated with the proposed study of this paper, which are considered important for the selection of an oil and gas project. The first factor, net present value, is determined by discounting future cash flows to the present or base time. In a present worth comparison of different oil and gas projects, the net present value of the costs associated with each investment are converted to a present value. Obviously, more positive values are more interesting for investment. The process of finding present values is called discounting and the interest rate applied to calculate present values is called the discount rate. Obviously, it is very important to measure the present value under different discount rate to have a better image on the project's income when the interest 
rates change. One important point with net present value is that when we intend to use this method to compare different projects they all have to have the same duration, otherwise, the results would be misleading. To handle this problem, we may repeat projects with shorter finishing times in our calculations.

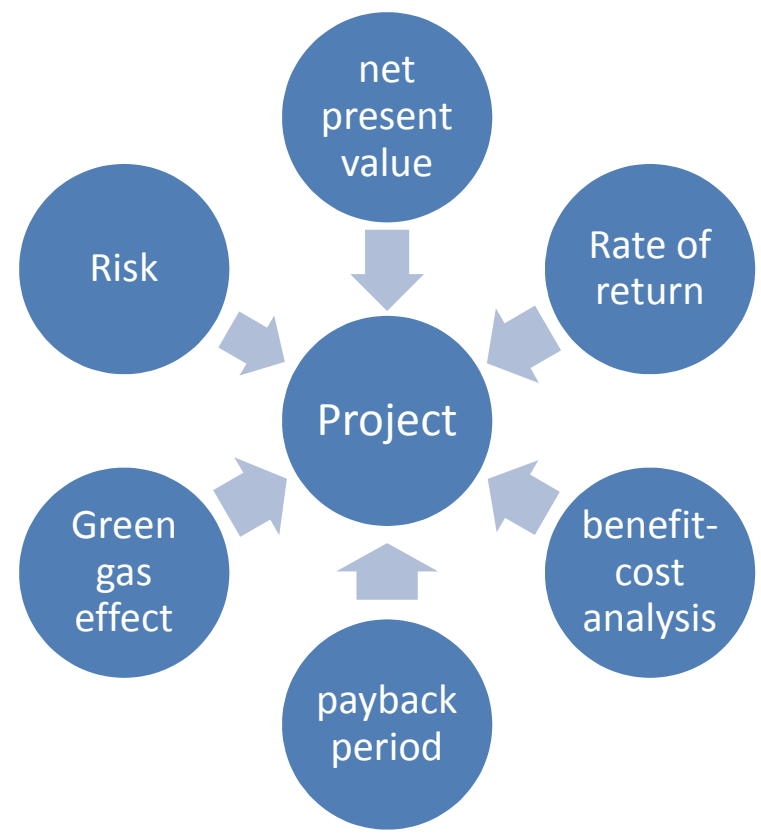

Fig. 1. The structure of the proposed study

The second item, rate of return (ROR), analyzes a major purchase or project and allows us to consider the time value of money. Rate of return is, by definition, the interest rate at which the present worth of the net cash flow becomes zero. Obviously, higher ROR rates are more beneficial. The important point with this method is that the rate is not unique and we may have different rates for a project.

The third factor, cost-benefit analysis (CB), is adopted as an analytical framework to evaluate the net benefit of a project. Benefit-cost analysis, also stated to as cost-benefit analysis, is a technique of comparison in which the outcomes of an investment are assessed in monetary terms and under separate categories of costs/benefits. The amounts are then converted to annual equivalents or present worth for comparison.

Payback period is another form of financial analysis, which simply considers the capital cost of the investment and compares that value to the net annual revenues that investment could yield. The use of the payback period as a capital budgeting decision rule specifies that all independent projects with a payback period less than a specified number of years should be accepted (Mahmoodzadeh et al., 2007).

Risk is another factors considered in this study and it is involved with different issues such as the price of oil and gas, government regulations, etc. To better understand the concept of risk, consider two oil and gas projects where the first one has better net present value but it is feasible only when the price of oil is higher than $50 \$$ while the second project yields a lower net present value but it could feasible even when the price of oil is less than $40 \$$. In this study we consider higher risk value for the first project compared the second project. The last factor is associated with environmental issues as well as the green gas effects. In this study, we are more interested in investing in projects, which are more environmental friendly. 
2.2 Technique for Order of Preference by Similarity to ideal Solution (TOPSIS)

The technique for Order of Preference by Similarity to ideal Solution (TOPSIS) is considered as a multi criteria decision analysis method developed for the first time by Hwang and Yoon (1981). The technique is based on the concept that the best alternative has the shortest geometric distance from the positive ideal solution (PIS) and has the longest geometric distance from the ideal negative solution (NIS). A PIS maximizes the benefit criteria / attributes and minimizes the benefit criteria. Following are the important steps of TOPSIS:

Step 1: Identifying evaluation attributes

Identification of the objectives and the evaluation attributes for the study.

Step 2: Evaluation matrix and obtaining normalized decision matrix

Prepare an evaluation matrix, which consists of $m$ attributes and $n$ criteria. The intersection of every attribute and criteria is given as $x_{i j}$. Normalize the decision matrix using the following equation:

$$
R_{i j}=\frac{x_{i j}}{\sqrt{\sum_{j=1}^{M} x_{i j}^{2}}}
$$

where $\quad i=1,2, \ldots . . m$ and $\quad j=1,2, \ldots . n$

Step 3: Obtain weighted normalized matrix

Decide the relative importance (i.e. weights) of various attributes with respective to the objective in such a way that the sum weights of all attributes equals to 1 .

$$
\sum_{i=1}^{n} w_{i}=1
$$

Obtain the weighted normalized matrix by multiplying the normalized decision matrix by its associated weights. The weighted normalized decision matrix is formed as

$$
V_{i j}=w_{j} \times R_{i j}
$$

where $i=1,2, \ldots . . m, j=1,2, \ldots . n$ and $w_{j}$ is the weight of the $j^{\text {th }}$ attribute.

Step 4: Determine positive ideal $(V+)$ and negative ideal $(V$-) solution

The positive ideal solution (PIS) and negative ideal solution (NIS) are chosen as follows:

$$
V^{+}=\left(V_{1}^{+}, V_{2}^{+}, \ldots, V_{n}^{+}\right) \text {maximum values and } V^{-}=\left(V_{1}^{-}, V_{2}^{-}, \ldots, V_{n}^{-}\right) \text {minimum values }
$$

Step 5: Calculate separation measures using $n$-dimensional Euclidean distance

Separation of every alternative from the positive ideal solution (PIS) and negative ideal solution (NIS) is calculated using following formulae:

$$
S_{j}^{+}=\sqrt{\sum_{i=1}^{n}\left(V_{i j}-V_{i}^{+}\right)^{2}} \text { and } S_{j}^{-}=\sqrt{\sum_{i=1}^{n}\left(V_{i j}-V_{i}^{-}\right)^{2}}
$$

where $j=1,2, \ldots, \mathrm{N}$. 
Step 6: Calculate closeness coefficient $(P)$

Closeness coefficient $\left(\mathrm{P}_{\mathrm{j}}\right)$ for every strategy is calculated as follows:

$$
P_{j}=\frac{S_{j}^{-}}{S_{j}^{+}+S_{j}^{-}}
$$

Step 7: Determine percentage contribution of strategy:

The percentage contribution of every strategy is calculated as follows:

$$
P C_{j}=\frac{P_{j}}{\sum P_{j}} \times 100
$$

\section{Data collection}

In this survey, since we did not have access to actual numbers, we show the implementation of the proposed method through an example. Table 1 demonstrates the criteria along with the results of TOPSIS ranking.

Table 2

\begin{tabular}{|c|c|c|c|c|c|c|c|}
\hline \multicolumn{8}{|c|}{ Criteria } \\
\hline City & $\begin{array}{l}\text { Net present } \\
\text { value }\end{array}$ & Rate of return & Benefit-cost & $\begin{array}{l}\text { Payback } \\
\text { period }\end{array}$ & $\begin{array}{c}\text { Green gas effect } \\
\mathrm{Co}_{2} \text { emission }\end{array}$ & Risk & Rank \\
\hline 1 & 13,956 & 12.5 & 321 & 4.2 & 5,157 & 0.5 & 0.2660 \\
\hline 2 & 14,435 & 3.5 & 387 & 0.9 & 4,808 & 0.3 & 0.2054 \\
\hline 3 & 30,526 & 14.5 & 511 & 2.1 & 4,205 & 2.3 & 0.3181 \\
\hline 4 & 17,111 & 2 & 485 & 6 & 3,888 & 8.1 & 0.6534 \\
\hline 5 & 11,316 & 8 & 384 & 2.4 & 4,852 & 2.4 & 0.3166 \\
\hline 6 & 21,790 & 13 & 670 & 1.6 & 3,196 & 0.3 & 0.2053 \\
\hline 7 & 10,090 & 3.5 & 430 & 3.8 & 4,922 & 0.6 & 0.2367 \\
\hline 8 & 10,596 & 4 & 370 & 5.1 & 4,493 & 2.5 & 0.3427 \\
\hline 9 & 21,842 & 19 & 574 & 0.4 & 4,728 & 9.4 & 0.7285 \\
\hline 10 & 15,670 & 23.5 & 1,773 & 3.2 & 3,400 & 1.1 & 0.2430 \\
\hline 11 & 12,246 & 14 & 1,993 & 2.4 & 3,265 & 0.3 & 0.1421 \\
\hline 12 & 21,435 & 5 & 337 & 5.7 & 6,433 & 0.8 & 0.2817 \\
\hline 13 & 12,219 & 7.5 & 372 & 0.8 & 8,463 & 0.9 & 0.2322 \\
\hline 14 & 13,156 & 7 & 380 & 3.4 & 5,302 & 3.0 & 0.3566 \\
\hline 15 & 19,183 & 13 & 222 & 0.6 & 7,386 & 0.8 & 0.2554 \\
\hline 16 & 13,316 & 4 & 252 & 1 & 10,400 & 0.9 & 0.2373 \\
\hline 17 & 17,111 & 2 & 540 & 4.6 & 3,888 & 1.4 & 0.2648 \\
\hline 18 & 14,040 & 8.5 & 445 & 4.5 & 4,374 & 1.1 & 0.2698 \\
\hline 19 & 18,541 & 16 & 558 & 1.3 & 2,980 & 0.1 & 0.2218 \\
\hline 20 & 13,252 & 4.5 & 196 & 0.8 & 5,126 & 1.2 & 0.2512 \\
\hline 21 & 8,943 & 9.5 & 361 & 3.7 & 4,816 & 5.7 & 0.5662 \\
\hline 22 & 13,799 & 7.5 & 255 & 0.9 & 6,298 & 3.0 & 0.3465 \\
\hline 23 & 32,803 & 22 & 366 & 0.4 & 4,125 & 0.8 & 0.2780 \\
\hline 24 & 23,966 & 7.5 & 346 & 1.7 & 4,713 & 3.3 & 0.3660 \\
\hline 25 & 15,699 & 9.5 & 780 & 2.8 & 3,980 & 0.9 & 0.2178 \\
\hline 26 & 20,043 & 6.5 & 517 & 0.7 & 4,693 & 0.8 & 0.2095 \\
\hline 27 & 20,480 & 13 & 412 & 5.9 & 7,368 & 2.9 & 0.3978 \\
\hline 28 & 13,988 & 4 & 335 & 4.1 & 6,542 & 2.6 & 0.3363 \\
\hline 29 & 23,079 & 5 & 254 & 2.9 & 6,828 & 0.9 & 0.2521 \\
\hline 30 & 20,630 & 11.5 & 528 & 1.9 & 4,776 & 1.1 & 0.2402 \\
\hline 31 & 17,618 & 45 & 1,331 & 1 & 3,163 & 0.1 & 0.3293 \\
\hline 32 & 17,666 & 9.5 & 512 & 1.3 & 4,138 & 0.6 & 0.2151 \\
\hline 33 & 21,981 & 14.5 & 1,993 & 0.4 & 1,694 & 0.7 & 0.1456 \\
\hline 34 & 14,062 & 6.5 & 584 & 0.7 & 4,079 & 4.3 & 0.4150 \\
\hline 35 & 26,159 & 10.5 & 551 & 1.2 & 3,655 & 0.2 & 0.2035 \\
\hline 36 & 12,626 & 1 & 1,497 & 2.5 & 3,914 & 0.9 & 0.3978 \\
\hline 37 & 15,429 & 4.5 & 473 & 5.5 & 4,044 & 0.1 & 0.2503 \\
\hline
\end{tabular}

Input parameters for 37 projects along with the result of TOPSIS method 
Note that the weights of each criteria has been determined through the implementation of AHP method. The study assumes there are 37 oil and gas projects for investment. The ranking obtained through the implementation of TOPSIS is given which is calculated based on the procedure explained in section 2 .

\section{Conclusion}

We have discussed different issues associated with the investment in oil and gas projects and explained that there are presently many issues such as environment, risk, etc. in addition to regular cost/benefit outcomes, which influence significantly on oil and gas investments. The oil and gas industry has been also mainly influenced by the price of oil and gas and in some events, many production units have been forced to shut down solely because of low price of oil and gas. Environmental issues are other important factors, which may put pressure on Canada's political affairs since the country has strong commitment to reduce green gas effect. In this paper, we have introduced a multi-criteria decision making method to rank various projects in terms of investment. The proposed study has considered different investment factors including net present value, rate of return, benefit-cost analysis and payback period along with the intensity of green gas effects for ranking present oil and gas projects in Canada. Using TOPSIS technique, as a multi criteria decision making technique, the study has demonstrated the implementation of the proposed method using a case study.

\section{References}

Badiru, A. B., \& Osisanya, S. O. (2016). Project management for the oil and gas industry: a world system approach. CRC Press.

Charpentier, A. D., Bergerson, J. A., \& MacLean, H. L. (2009). Understanding the Canadian oil sands industry's greenhouse gas emissions. Environmental Research Letters, 4(1), 014005.

Fidler, C., \& Noble, B. (2012). Advancing strategic environmental assessment in the offshore oil and gas sector: Lessons from Norway, Canada, and the United Kingdom. Environmental Impact Assessment Review, 34, 12-21.

Hwang, C.L., \& Yoon, K.P. (1981) Multiple attribute decision making: methods and applications. New York: Springer-Verlag.

Mahmoodzadeh, S., Shahrabi, J., Pariazar, M., \& Zaeri, M.S. (2007). Project selection by using fuzzy AHP and TOPSIS technique. International Journal of Social, Management, Economics and Business Engineering, 1(6), 324-329.

Marcil, J. S., Lavoie, J., Mechti, N., Lavoie, F., Massé, L., \& Dorrins, P. (2016, April). Natural fractures characterization and horizontal drilling of an oil-prone Devonian carbonate-birth of a new major play in eastern Canada. In International Conference and Exhibition, Barcelona, Spain, 3-6 April 2016(pp. 139-139). Society of Exploration Geophysicists and American Association of Petroleum Geologists.

Saaty, T. L. (1989). Group decision making and the AHP. The analytic hierarchy process, 59-67.

Thomas, M., Pidgeon, N., Evensen, D., Partridge, T., Hasell, A., Enders, C., ... \& Bradshaw, M. (2017). Public perceptions of hydraulic fracturing for shale gas and oil in the United States and Canada. Wiley Interdisciplinary Reviews: Climate Change, 8(3).

Van Hinte, T., Gunton, T. I., \& Day, J. C. (2007). Evaluation of the assessment process for major projects: a case study of oil and gas pipelines in Canada. Impact Assessment and Project Appraisal, 25(2), 123-137.

Zadeh, L. A. (1997). Toward a theory of fuzzy information granulation and its centrality in human reasoning and fuzzy logic. Fuzzy sets and systems, 90(2), 111-127.

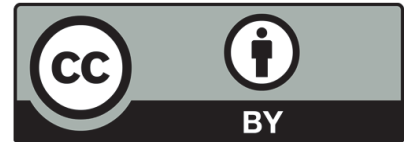

(C) 2017 by the authors; licensee Growing Science, Canada. This is an open access article distributed under the terms and conditions of the Creative Commons Attribution (CC-BY) license (http://creativecommons.org/licenses/by/4.0/). 